\title{
The role of amphibian prey in the diet and growth of giant water bug nymphs in Japanese rice fields
}

\author{
Shin-ya Ohba $\cdot$ Hitoshi Miyasaka - Fusao Nakasuji
}

Published online: 26 September 2007

(C) The Society of Population Ecology and Springer 2007

\section{Erratum to: Popul Ecol}

DOI 10.1007/s10144-007-0058-0

The original version of this article unfortunately contained a mistake. The wrong version of Fig. 2 was published. The correct figure, together with its legend, appears on the following page.

The online version of the original article can be found under doi:10.1007/s10144-007-0058-0.

S. Ohba $(\varangle) \cdot$ F. Nakasuji

Laboratory of Insect Ecology,

Graduate School of Environmental Science,

Okayama University, Tsushima,

Okayama 700-8530, Japan

e-mail: oobah8ag@yahoo.co.jp

H. Miyasaka

Center for Marine Environmental Studies,

Ehime University, Matsuyama, Japan 
Fig. 2 Five prey groups in the diet of $K$. deyrolli nymphs at Fukusawa in 2003 (top),

Uekidani in 2004 (middle), and

Chuo in 2004 (bottom).

Numerals show sample sizes

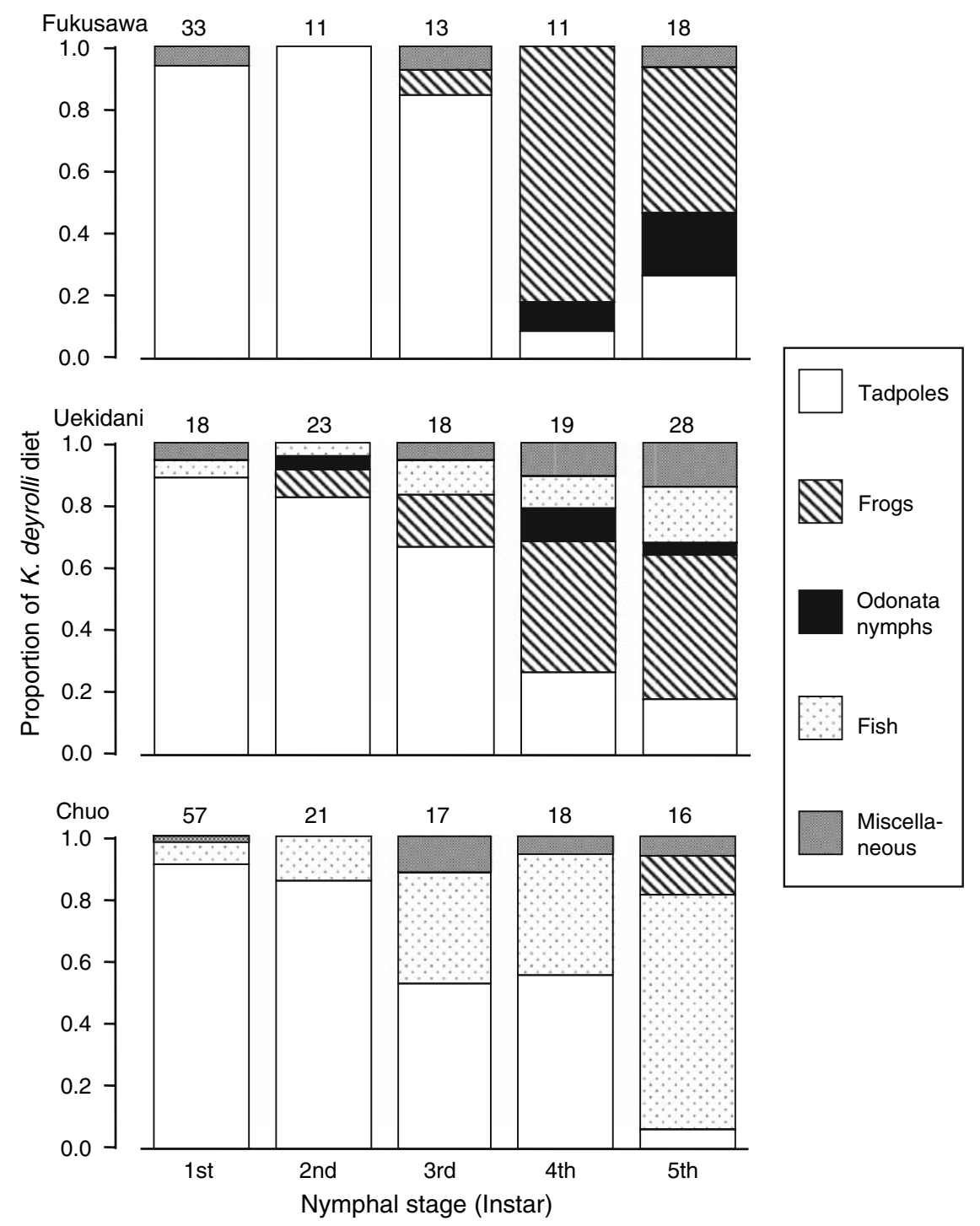

